\title{
A SOCIEDADE CIVIL E O ESTRANGEIRO*
}

WERNER SCHIFFAUER

Muito distante da utopia de ser uma barreira contra o ódio aos estrangeiros, a civil society parece engendrar em seu próprio seio a aversão ao que é diferente. São os países europeus, de toda forma, que hoje reagem com mais violência ao fluxo migratório relacionado ao colapso da ordem mundial.

A civil society, tal como se desenvolveu no norte da Europa, funda-se na idéia do indivíduo em um contexto de troca livre. Poder-se-ia dizer que trata-se de uma forma de sociedade cujas instituições centrais, valendo-se de chamadas para denominá-las, são o mercado, o forum e o palco. O mercado representa a troca livre e racional de bens; o forum representa todas as instituições do público político, em que o intercâmbio livre de conviç̧ões forma a Vontade Geral e em que um acordo sobre o bem comum é alcançado; e por último, o palco deveria (pars pro toto) representar os espaços do público cultural, onde uma cultura de trocas simbólicas desenvolve-se - e em que classificações sobre isso impõem-se e valores cristalizam-se (muitas vezes de um modo não muito explícito). Essas instituições são também encontradas individualmente em outras sociedades - a civil society caracteriza-se pelo estreito vínculo estabelecido entre as três instituições.

A cultura da civil society tem uma peculiaridade antropológica: para que a troca livre possa ocorrer, uma forma específica de socialização é necessária. É preciso romper com a idéia, de outra forma universalmente válida, de que as relações primárias (família, amizade e relações de leal-

* "Civil Society and Foreigners. Boundaries Delimitations in Three Political Cultures". Texto apresentado no Seminário "Terra natal, terra estrangeira - migrações na Europa nos anos 90", promovido pelo Instituto Goethe de São Paulo em colaboração com o CEDEC e o IDESP, setembro de 1994. Tradução de Álvaro de Vita. 
dade) devem também ter uma importância primeira, o que implica, por assim dizer, uma estrutura concêntrica do mundo social: sentimo-nos - bastante literalmente - mais compromissados com os que nos são mais próximos; quanto maior e mais inclusiva torna-se a unidade social em questão, mais decai o grau de lealdade a ela devotado. De outra parte, na Europa o ideal de que o geral é mais importante do que o particular foi aceito, e o interesse comum prevalece sobre o individual. Em caso de conflito, o geral (a norma, em termos formais, e o bem comum, substancialmente) prevalece sobre o individual.

Pode-se perceber o que esse ideal de socialização exige do indivíduo pelo problema da distribuição de posições sociais. Segue-se do ideal que essa distribuição deve ser feita de forma racional, sem consideração por determinadas pessoas, e que se deveria escolher o melhor e não o mais próximo. Aqueles que seguem atribuindo uma importância primeira às relações primárias são culpados de nepotismo, de corporativismo, de favoritismo. Dessa forma, uma imposição específica estabelece-se: seu conteúdo positivo é o de que, ao distribuírem-se posições, às vezes é preciso trair aqueles que nos são próximos; seu conteúdo negativo é o de que às vezes vemos alguém que nos é completamente estranho ser preferido na distribuição de posições. Em resumo, trata-se de uma forma extremamente efetiva de socialização - mas que é também bastante problemática.

Um problema desse tipo de socialização é o estabelecintento de fronteiras. Fronteiras estabelecidas de fora determinam o âmbito em que essa imposição de modernidade deve ser válida. Com respeito à política, elas determinam o grupo ao qual se deve legitimamente estar subordinado - elas estabelecem o grupo cujas decisões, em sua maior parte, devem ser aceitas, ainda que impliquem desvantagens individuais. Com respeito à economia, essas fronteiras determinam o grupo de pessoas às quais aplica-se a norma "que vença o melhor". Por isso, não é coincidência que exatamente a história da cultura européia seja a história do estabelecimento de fronteiras (e por essa razão, obviamente, uma história de extrapolação de fronteiras). Cada abertura, deslocamento ou transformação de fronteiras significa uma diminuição do controle, assim como de oportunidades. É o que estamos presenciando na Alemanha de hoje. Isso também designa aquele que talvez seja o dilema central da cultura pública: de sua lógica interna, de seu conceito, ela é conduzida em direção à universalidade; em termos práticos, entretanto, cada expansão significa um aumento de imposição - o que cria problemas de legitimação: cada vem mais, são autoridades anônimas que decidem pelo indivíduo, que, por sua vez, precisa se defrontar com cada vez mais 
competidores. Em verdade, o desenvolvimento da cultura pública poderia ser descrito como uma história de reestruturação de fronteiras: a integração de novos grupos freqüentemente levou à exclusão de outros grupos (ou à exclusão do mesmo grupo em um outro nível): não é coincidência que a integração legal dos judeus tenha sido respondida com novas formas de discriminação.

Devido a sua estrutura, a civil society é o tipo de sociedade que, em razão de sua ênfase no geral, em princípio permite ao estrangeiro participar do jogo social; entretanto, devido às imposições que a ela estão relacionadas, esse também é um tipo de sociedade que seguidamente exclui o estrangeiro. O estrangeiro é integrado $e$ discriminado.

Como essa relação entre integração e exclusão apresenta-se em cada caso particular, isso depende das características específicas de cada civil society, e de cada solução específica à relação entre o indivíduo e o geral na cultura pública.

\section{FRANÇA}

Na cultura francesa, o indivíduo relaciona-se ao geral pela idéia da universalidade do senso público. Regras claras existem - que em princípio têm aplicação universal - às quais todos estão igualmente sujeitos. A instituição que mais claramente expressa essa idéia, em minha opinião, é o onipresente concours: são as competições e os exames de seleção. O concurso é um procedimento absolutamente racional, universal e igualitário de distribuição de posições sociais.

A racionalidade, a igualdade e a universalidade correspondem a uma cultura centralista e notavelmente (em uma escala européia) homogênea: "na França, a monarquia absoluta e mais tarde o jacobinismo da República 'indivisível' eliminaram totalmente as peculiaridades regionais, lingüísticas e religiosas". No espaço público, elas (as peculiaridades) nada tinham e nada perderam. O princípio do geral, da nação, foi construído precisamente em oposição a todos os particularismos culturais. Dumont escreve que "[na cultura francesa], sou um ser humano por natureza e um francês por acaso". A nação é, por assim dizer, uma estrutura institucional para a emancipação do indivíduo.

Aqui a liberdade associa-se fortemente, se é que a ela não se identifica, à igualdade. É algo muito característico que na França se tenha buscado garantir a integração dos estrangeiros por meio de leis antidiscriminação - as mais severas de toda a Europa. Esta é "uma política de tratamento igual e de punição à discriminação", observa Costa- 
Lascoux - uma política que visa à igualdade jurídica de indivíduos e que não reconhece direitos de grupos (tal como ocorre, por exemplo, em um sistema de cotas).

Entretanto, surge aqui uma dimensão problemática: a liberdade, obviamente, também significa a possibilidade da gênese de diferenças, que freqüentemente têm uma tendência de romper a distinção nítida e frágil entre o público e o privado. Na realidade, parece-me que essa discussão francesa - multifacetada e muito diferenciada - gira em torno da solução do problema da diferença. Aqui só posso indicar alguns de seus aspectos. Antes de mais nada, o discurso da igualdade parece encontrar refúgio na esquerda. Robert Grillo analisa dois tipos de discurso sobre estrangeiros. Um deles é inclusivo e igualitário, e centraliza-se no conceito de immigré - que evoca a solidariedade da "classe trabalhadora internacional". Por isso, não é surpreendente que esse discurso seja particularmente saliente nas fileiras da central sindical comunista, a CGT. O outro discurso é excludente e centrado no conceito do étranger; as idéias que a ele associam-se são as de "nacionalidade", "cultura", "língua" e "raça". Segundo membros da CGT, trata-se de um conceito burguês e divisório. De outra parte, é claro que a esquerda não pode ignorar inteiramente a etnia; em geral, ela é classificada no campo conceitual como uma "contradição secundária". Um problema que em especial surge nessa área decorre do fato de que qualquer ênfase cultural mais forte, tal como a reivindicação do direito a ser diferente, o droit à la difference de 1968, muito rapidamente converte-se em seu oposto e é empregado pela direita como um novo discurso de exclusão. Essa reivindicação que no passado foi progressista converte-se em seu oposto pela ênfase que agora é colocada no direito do povo francês a suas peculiaridades - resultando assim não em tolerância e sim em seu oposto: intolerância.

Tendo em vista o pano de fundo de um debate estruturado dessa forma, torna-se claro porque a "questão do véu", que eclodiu em Creil, causou tanto barulho. Líderes religiosos de Creil exigiram uma "discriminação positiva" de jovens muçulmanas que freqüentam escolas públicas: para eles, as muçulmanas devem ter o direito de usar o véu, de não participar de aulas de esporte e de música. Nesse caso, evidentemente, o direito à diferença, isto é, o direito a ser diferente, tornou-se uma questão legal e isso na área extremamente delicada do laicismo. É claro que, com essa demanda, o público francês se defrontou com o "heterogêneo" - com uma demanda que simplesmente não cabia nas categorias usuais, que desafiava as classificações. Na sociedade francesa, a reivindicação de discriminação positiva só pode se apresentar como um paradoxo inquietante. 


\section{GRÃ-BRETANHA}

Na Grã-Bretanha, desenvolveu-se uma solução para a relação entre o indivíduo e a sociedade que em muitos aspectos passa a impressão oposta da resposta francesa. A liberdade e a igualdade são vistas de forma completamente diversa na Grã Bretanha.

Tal como a nação francesa, a britânica originou-se de uma forma estatal já existente. Entretanto, enquanto o conceito do Estado francês desenvolveu-se por inúmeros processos de reestruturação radical (durante o Absolutismo, durante a Revolução Francesa, assim como nas Revoluções Constitucionais de 1810 e 1848), ao que parece a forma britânica de relação (indivíduo-sociedade) desenvolveu-se de um modo orgânico. Isto afeta, para começar, o Estado como um todo: a relação do todo com suas partes individuais surgiu de uma relação especial - a Grã-Bretanha não é um campo legal homogêneo. No entanto, a relação entre as autoridades locais e o governo central também desenvolveu-se organicamente: da posição forte da nobreza feudal, assim como das corporações urbanas, emergiu uma ampla e duradoura autonomia das administrações locais, que mantiveram o controle sobre vastos domínios.

Enquanto na França a relação entre o indivíduo e o Estado parece ser deliberada e racional, na Grã-Bretanha ela se revela espontânea e confusa: ela consiste de um conjunto de direitos específicos e de peculiaridades locais. Enquanto na França "a igualdade e o racionalismo ... exprimem-se, e são garantidos, em constituições estritamente racionais e habilidosamente elaboradas", a Constituição inglesa é "irracional", "confusa" e consiste no direito costumeiro, observa Ernst Troeltsch.

Nessa cultura não-igualitária constituiu-se um conceito de liberdade que está relacionado sobretudo à inviolabilidade da pessoa e à liberdade de movimento. As esferas da vida do indivíduo - os âmbitos privados e os direitos de grupo - são cuidadosamente protegidas, tanto pelas leis como por uma sofisticada cultura de convenção social. Esta é a base (a única, aliás) sobre a qual um notável pluralismo de estilos de vida pode se desenvolver.

Como se produz uma Vontade Geral nessa cultura? Nesse caso, o garante da cultura pública parece ser menos a autoridade política (aqui o ceticismo reina) do que a confiança no conflito social. Um modelo para isso pode ser a competição esportiva de equipes, que não por acaso foi criada na Grã-Bretanha - com todas as suas implicações em termos de normas e jogo limpo, mas também de áspero conflito. Passando-se para a esfera pública, isso significa uma cultura de discussão pública, em que o embate é muito mais duro do que na Alemanha. É nesse contexto que se 
passa o conflito com os estrangeiros e a questão dos direitos de grupo. Isso se aplica tanto ao discurso da exclusão quanto ao da delimitação.

Antes de mais nada, salta à vista que o racismo britânico associa-se ao Partido Trabalhista (enquanto na França o racismo associa-se à burguesia). Isso pode ser compreendido a partir dó contexto britânico da criação do nicho e da subcultura. A fórmula parece ser a seguinte: quanto mais próximas as relações de interdependência (com respeito a trabalho, moradia e lazer), tanto mais pronunciada e xenófoba se torna a cultura dos trabalhadores. O exemplo clássico é o East End de Londres. Lá desenvolveu-se uma marcada auto-consciência (a de um genuíno East Ender) que associa-se a pretensões territoriais explícitas: uma pessoa se torna um East Ender mostrando que o East End lhe pertence. Dessa forma, o racismo britânico surge mais fortemente relacionado a um grupo específico do que o racismo francês ou alemão.

Enquanto os imigrantes permanecem "entre eles mesmos", em suas próprias áreas residenciais e atividades, eles não são "problemáticos". Eles têm sua vizinhança e suas normas de comportamento, e nós temos as nossas. Entretanto, tão logo torna-se claro que os imigrantes não querem continuar aceitando essas restrições, e passam, por exemplo, a reivindicar seus direitos sociais, os sentimentos para com eles se convertem em um racismo muito mais agressivo.

Não só o discurso da exclusão, mas também o discurso da delimitação torna os direitos de grupo mais fortes na Grã-Bretanha do que em qualquer outra parte na Europa. No curso da integração coletiva, acordos foram alcançados - muitas vezes no nível local -, freqüentemente em um processo tipicamente britânico de criação de um compromisso e da realização de acordos com setores específicos das autoridades locais. Penso ser notável a reação de uma observadora francesa a essa política de discriminação positiva: "Em um sistema democrático, cujo princípio é a lei comum, o crescente isolamento de certos estratos da população, que em certa medida vive em guetos na Grã-Bretanha, leva a contradições. Será recomendável que existam escolas muçulmanas ou paquistanesas, em Birmingham por exemplo, que as garotas sejam excluídas de certos conteúdos de ciências naturais, tenham aulas de natação separadas (...)? Deve-se ser favorável a isso em nome da luta contra a discriminação?" Em outras palavras, a observadora francesa percebe que cada política de discriminação positiva leva a um fortalecimento ainda maior da desigualdade.

No sistema britânico, as organizações de imigrantes que agem como representantes de interesses e como partes negociadoras desfrutam de uma posição forte. Isso também significa - internamente - uma competição estrutural entre frações. É este o pano de fundo a partir do qual a 
logica do "caso Rushdie" — na medida em que esteja restrito à GrãBretanha - torna-se compreensível.

Estou de acordo com a teoria de Kepel de que se trata de uma tentativa dos imãs de se consolidarem como líderes da comunidade. De acordo com Kepel, o caso Rushdie foi "um teste para a capacidade dos imãs de arrancar concessões políticas do governo: eles exigiram a proibição do livro [de Rushdie], prometendo em compensação acabar com a agitação nos guetos. Eles se colocaram um objetivo parcial, que deveria fortalecer seu papel enquanto intermediários, e se dispuseram a restabelecer a paz social em troca de uma retribuição correspondente (o fortalecimento do sistema religioso da comunidade)".

A minha impressão é a de que o "caso Rushdie" coloca o público britânico diante da heterogeneidade, de uma forma similar ao que ocorreu com o público francês no "caso do véu". E isso precisamente porque a reivindicação de fortalecimento de direitos de grupo acaba por se associar à reivindicação de intolerância — por isso o público britânico, da mesma forma que o francês no "caso do véu", se viu diante de um problema espinhoso. Isso provavelmente teria se tornado ainda mais claro se a Fatwa de Khomeini* não tivesse simplificado novamente a diferença pela radicalização excessiva.

\section{ALEMANHA}

A relação entre o indivíduo e o geral na cultura política alemã encontra uma solução completamente distinta daquela dos franceses e dos ingleses. A chave, para mim, parece ser um conceito diferente de liberdade. Enquanto na França ela vem associada à igualdade e na GrãBretanha à inviolabilidade, na Alemanha a liberdade é citada com uma surpreendente freqüência junto com o termo "responsabilidade": somente aqueles que são capazes de responsabilidade deveriam se envolver no intercâmbio livre a partir do qual cristaliza-se a Vontade Geral.

Essa diferença de conotação da idéia de liberdade corresponde a diferentes idéias de generalidade. A mim parece-me que tanto na França quanto na Grã-Bretanha acredita-se que para que o bem-estar público seja alcançado, basta que as premissas sociais estejam garantidas: na França, isso se verifica quando a igualdade é garantida e quando os indivíduos são fiéis às normas; na Grã-Bretanha, quando os direitos de liberdade permanecem intocados e quando são respeitadas as normas da troca de socos. Em ambos os ca-

* A sentença de Khomeini condenando Rushdie à morte (N.T.). 
sos, (1) a obediência a normas é necessária, o que por sua vez (2) permite uma competição social ordenada, o que por fim (3) conduz ao bem-estar geral. Essa confiança está ausente da cultura política alemã. A responsabilidade no que concerne somente às regras do jogo parece insuficiente e "apenas superficial": antes e depois da aprovação da norma, uma identificação com o geral é necessária (uma "dedicação ao todo", diz Troeltsch). Somente quando o geral é interiorizado, é possível e permitido ser livre.

Caso se prefira assim, pode-se pensar a relação do indivíduo com o geral na cultura política alemã em termos dialéticos. O conceito decisivo parece ser o de indivíduo-geral de Schiller. Isso nos leva à seguinte fórmula: a referência ao geral e ao individual somente é possível se o geral realiza-se no individual e se o individual realiza-se no geral. Primeiramente, olhemos para o lado do geral. Em que tipo de discurso o bem-estar geral deve ser decidido na cultura alemã? A resposta é: no círculo dos melhor informados, os especialistas. A construção alemã de opiniões especialistas, o denominado "conselho do sábio", parece-me algo notável. Antes de cada rodada de discussões salariais, os institutos de pesquisa econômica manifestam sua opinião especializada, estabelecendo o que é "razoável" - antes e independentemente da rodada efetiva de negociações salariais. Evidentemente, desvios excessivos desse parâmetro colocarão problemas de legitimação para os parceiros da negociação salarial.

Há um total ceticismo com relação à solução por via do conflito social autônomo: há o temor de que nesse caso, se um quadro de referência claro não é previamente estabelecido, o interesse puro e a força de determinados grupos prevalecerão à custa do bem-estar geral. Em resumo, o bem-estar geral é definido por uma comissão de especialistas, "livres da pressão das ruas", em um discurso livre de dominação. Com sua burocracia, a República Alemã se permite o luxo um tanto dispendioso de uma classe de especialistas afastados do jogo social do poder e comprometidos com o bem-estar público. A forma institucional pela qual o indivíduo se realiza no geral é a da república dos especialistas.

Olhemos agora para o lado do indivíduo: como o indivíduo é levado a pensar, sentir e agir de uma forma socialmente responsável, em outras palavras, como o geral se realizará no indivíduo? A resposta formulada por Schiller é: pela educação. A pedagogia transmite o geral e o individual ao indivíduo. Há não muito tempo atrás, dizia-se que alguém começa a ser uma pessoa quando termina a escola secundária. A atitude expressa por essa frase é a de que na realidade somente a pessoa internamente cultivada é uma "pessoa" no sentido pleno da palavra, capaz de assumir direitos e responsabilidades como um participante da sociedade. $\mathrm{O}$ 
fato de a alocação de posições na Alemanha dar uma importância fundamental à carreira acadêmica também deve ter relação com essa atitude.

Essa atitude pedagógica também exprime a percepção alemã da individualidade, que assume a forma de uma certa preocupação de "ser justo no caso individual". A instituição do concurso jamais poderia ganhar aceitação nesse país, porque passaria a impressão de ser um método de alocação de recursos excessivamente mecânico. Esta também parece-me ser a razão pela qual uma política antidiscriminação (mediante a instituição de cotas) dificilmente seria aceita na Alemanha.

Toda essa estrutura tem uma característica burguesa em termos de educação. Isto deve ter alguma relação com a história da construção da nação alemã. No caso da Alemanha, diversamente dos casos de comparação aqui descritos, o que surgiu foi um nacionalismo de unificação: foi preciso primeiro criar a estrutura estatal. A implicação disso é a de que o critério de ser membro, para determinar quem pertencia à nação, teve que ser estabelecido culturalmente - "internamente".

Essa forma especial de pensar a relação do indivíduo com o geral, se de uma parte é eficiente (em 1925, Troeltsch falou com orgulho de uma "elevada capacidade organizacional dos alemães" - o que ainda podemos considerar cabível hoje, ainda que com um gosto amargo), de outra requer um grande esforço. Tal relação é jogada de forma tendenciosa para dentro do indivíduo, enquanto que em outras sociedades o intercâmbio [indivíduo-geral] é estabelecido entre os indivíduos. Acredito que a isso está relacionado um notável desejo de normalidade - de clareza, de calculabilidade.

Uma peculiaridade muitas vezes observada da cultura alemã relaciona-se diretamente a essa forma de pensar a relação do indivíduo com o geral. A cultura da introspeç̧ão, de identificação com o todo, de valorização positiva do Estado, guarda uma importante correlação com uma cultura social comparativamente fraca (em comparação com a Inglaterra e com a França). Há dificuldades para o estabelecimento de rituais da sociedade. As normas, a orientação que elas oferecem, e a civilité parecem contradizer o valor da introspecção (e os valores, a esta associados, da sinceridade e da honestidade). Sente-se a "superficialidade" dessas normas. A lógica desse conjunto de normas - tornar possível o trânsito social, ao mesmo tempo em que preserva-se a distância interior - mantém (e afirma) a estranheza, i.e., contradiz a exigência de identificação. Muito da falta de jeito no contato com os estrangeiros relaciona-se à civilidade fracamente estabelecida, e um contato que logo de início exija sinceridade, é simplesmente pedir demais. Entretanto, mais importante é uma segunda conseqüência: em uma cultura em que a identificação com o todo é valorizada como um pré- 
requisito à participação na sociedade, o estrangeiro encontra-se já de princípio em uma posição difícil. Como é possível extrair essa afirmação interior (e por isso invisível) de alguém que foi educado em uma cultura totalmente diferente? Será que o "estrangeiro" identifica-se só externamente [à comunidade], será que ele sente-se realmente comprometido com a comunidade? Acredito que o discurso antisemita nazista caracterizava-se exatamente por se fundar na idéia de que mesmo o judeu mais "assimilado" é "interiormente" cosmopolita, um indivíduo sem uma terra natal, etc.

Essa peculiaridade da cultura alemã deve ter relação com a manifestação de um discurso suspicaz dirigido exatamente ao estrangeiro que melhor conseguiu adaptar-se. Talvez essa seja a razão pela qual a conduta em relação aos estrangeiros oscila entre dois extremos, a saber, entre a assimilação individual e a supressão (física) do fato de a Alemanha ser um país de imigração.

Enquanto a variante conservadora do discurso da assimilação coloca os estrangeiros intransigentemente diante da exigência de adaptação, a versão liberal assume uma posição mais pedagógica e protecionista - é o ponto de vista da assimilação suave. É surpreendente que durante anos o discurso sobre os estrangeiros tenha sido dominado de forma praticamente exclusiva por educadores, enquanto sociólogos, cientistas políticos e antropólogos só muito hesitantemente manifestavam-se a respeito. Isso está relacionado com a tendência de já de início considerar os estrangeiros como um problema. Acredito ser adequado aqui um certn protecionismo: assim, pode-se observar uma relutância dos sociól ros para enfrentar e discutir as práticas delinqüentes - um comportamicnto que contrasta fortemente com a franqueza norte-americana para lidar com esses problemas.

O extremo oposto da assimilação é a supressão do fato de que os estrangeiros vivem aqui [na Alemanha] e aqui permanecerão. Uma das características mais notáveis do discurso alemão é a de que, a despeito de poderem ter um discernimento melhor do problema, os alemães continuam agarrando-se à idéia de que os assim chamados "trabalhadores convidados" (uma denominação que com o passar do tempo soa cada vez mais ridícula) talvez um dia venham a retornar a seus países de origem (isto é, agarram-se à idéia de que a Alemanha não é um país de imigração).

Essa cegueira à realidade segue a mesma lógica do pensamento de assimilação: em ambos os casos, o estrangeiro desaparece da nação. 


\section{A SOCIEDADE CIVIL E O ESTRANGEIRO}

\section{WERNER SCHIFFAUER}

Examinam-se as diferenças entre as formas de integração e de discriminação/exclusão dos estrangeiros em três países europeus: França, Grã-Bretanha e Alemanha. Argumenta-se que essas diferenças explicamse pelos distintos padrões de articulação entre o indivíduo e a esfera pública em cada uma dessas sociedades. Esses padrões, por sua vez, exprimem as noções de igualdade e de liberdade que são dominantes nas respectivas culturas políticas.

\section{CIVIL SOCIETY AND THE FOREIGNERS}

The differences between the models of integration and discrimination/exclusion of foreigners in three European countries - France, Great-Britain and Germany - are examined. It is argued that these differences are explained by the specific patterns of relationships between the individual and the public sphere in each of these civil societies. These patterns, in turn, embody the conceptions of equality and freedom that prevail in the respective political cultures. 